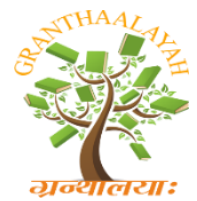

\author{
INTERNATIONAL JOURNAL OF RE
GRANTHAALAYAH \\ A knowledge Repository
}

Science

\title{
KNOWLEDGE, PERCEPTIONS AND PRACTICES ON CHOLERA TRANSMISSION AND PREVENTION MEASURES AMONG HEADS OF HOUSEHOLD MEMBERS IN KIGAMBONI MUNICIPALITY, DAR ES SALAAM, TANZANIA
}

\author{
Ramadhani H. Nauja ${ }^{* 1,2}$, Fidelis Charles Bugoye ${ }^{2}$, Rongo L. M. B. ${ }^{3}$ \\ ${ }^{*}$ School of Public Health and Social Sciences, Muhimbili University of Health and Allied \\ Sciences, Tanzania \\ *2 Department of Forensic Science and DNA Services, Government Chemist Laboratory \\ Authority, Tanzania \\ ${ }^{3}$ Departments of Occupation and Environmental Health, Muhimbili University of Health and \\ Allied Sciences, Tanzania
}

\begin{abstract}
Background: The Kigamboni Municipality has been experiencing recurrences of Cholera outbreaks. Objectives: The objective of this study was to evaluate knowledge, attitude and practices associated with Cholera transmission and prevention measures.

Method: A cross section descriptive study was adopted. A multistage sampling was used to select 410 respondents. An Interview schedule was used to obtain respondents opinions. Statistical Package for Social Sciences software version 20.0 was used to generate descriptive statistics which were further summarized into contingency tables.

Results: Results indicate that the most study population (70.2\%) had knowledge on causes, symptoms and the modes of transmission of Cholera. It was also found out that communities treat drinking water to make it safe $(76.8 \%)$ and are regular in hand washing with soap $(80.9 \%)$. The result also indicates that the community is willing to vaccination $(90 \%)$ and to adopting the Cholera prevention measures $(92.7 \%)$.

Conclusions and recommendations: The supply of pure water and adequate sanitation may serve as the prevention measures against the Cholera outbreak recurrences at Kigamboni Municipality.

Keywords: Cholera; Knowledge; Perceptions; Practices; Prevention; Kigamboni Municipality.

Cite This Article: Ramadhani H. Nauja, Fidelis Charles Bugoye, and Rongo L. M. B.. (2019). "KNOWLEDGE, PERCEPTIONS AND PRACTICES ON CHOLERA TRANSMISSION AND PREVENTION MEASURES AMONG HEADS OF HOUSEHOLD MEMBERS IN KIGAMBONI MUNICIPALITY, DAR ES SALAAM, TANZANIA.” International Journal of Research - Granthaalayah, 7(11), 28-48. 10.29121/granthaalayah.v7.i11.2020.331.
\end{abstract}




\section{Introduction}

Since the early 1800s, pandemics of cholera have affected millions (Harris et al., 2012). It is estimated that 1.3 to 4.0 million cases of cholera and 21000 to 143000 deaths occurs each year due to cholera worldwide (Ali et al., 2015). Cholera is one among the global public health and an indicator of underdevelopment (Adeneye et al., 2016). It is an acute enteric infection of the small intestines, caused by bacterium ingestion of Vibrio cholera and is transmitted through ingestion of contaminated food or water (Kadaleka, S., 2011). The signs and symptoms of cholera can vary from mild to severe such as severe watery diarrhea, vomiting and others, the promotion of improved hygiene practices and better access to safe water and sanitation facilities are the methods of preventing cholera due to being fecal-oral disease and rapid in its onset and spread (UNICEF., 2004). The control of cholera outbreak often requires changes to hygienic behavior (Phiri et al., 2015).

Cholera can be endemic or epidemic. A cholera endemic area is an area where confirmed cholera cases were detected during 3 out of the last 5 years with evidence of local transmission. A cholera outbreak or epidemic is an occurrence of at least 1 confirmed case of cholera with evidence of local transmission in an area where there is not usually cholera. (WHO., 2019). The risk factors associated with cholera outbreak includes little knowledge on the causes, modes of transmission, symptoms, prevention and control of the disease, attitudes towards the disease outbreak, low level of hygiene and environmental sanitation, poor hand washing behavior after visiting latrines, before and after eating food, during food preparation and during milking of the infants, poor tendency of using latrines, defecation behavior near sources of rivers, lack of treatment facilities and general treatment of drinking water such as water chlorination, low income and the socio economic status, use of street vended foods, bathing in the river, short distance to water sources and residents or the proximity to surface water, use of untreated water, low educational level, poor housing, unhygienic food handling, processing and preservation practices, poor sources of water for various domestic uses and improper and inadequate sewage disposal systems (Ali et al., 2015, Phiri et al., 2015, Kadaleka, S., 2011, Harris et al., 2012, Wahed et al., 2013, Lilje et al., 2015, Jerry et al., 2013, Makuza, N.J., 2002, Lindi, J.B., 2010 and Mpazi et al., 2005).

In Tanzania, the first 10 cholera cases were reported in 1974. Since1977 then, an outbreak were reported each year with a case fatality rate (CFR) averaging 10.5\% (between 1977 and 1992). The first major outbreak occurred in 1992 when 18'526 cases including 2173 deaths were recorded with a case fatality rate of $(C F R=11.7 \%)$. The outbreak of 1997 resulted in 40'249 cases and 2'231 deaths (CFR 5.54\%) (WHO., 2008).In 2006 occurred a wide coverage outbreak and a total of 14 297 cases including 254 deaths $(\mathrm{CFR}=1.8 \%)$ were reported from 16 regions out of 21 including Arusha, Dar es salaam, Dodoma, Iringa, Kigoma, Kilimanjaro, Lindi, Manyara, Mbeya, Morogoro, Mtwara, Pwani, Rukwa, Ruvuma, Tabora, Tanga. The most affected regions were Dar es Salaam (8965), Ruvuma (1 507) and Kigoma (1 030) while highest CFR were Mtwara (33.3\%), Iringa (12.7\%) and Dodoma (6.7\%) had the highest case fatality rates. Dar es Salaam was highly affected with 8,965 cases representing $62.7 \%$ of the total cases and 101 deaths (39.8\% of total deaths) (WHO., 2008).

The control and prevention of the disease outbreak has been linked to the access of safe water and improved sanitation. Tanzanian government with stakeholders tried to prevent and control an 
outbreak by providing health education and training with regards to cholera causes, signs and symptoms, its transmission and modes of control and preventions of the disease as well as purchasing supplies and equipment. However, the outbreak have been recurring every year despite the efforts above hence necessitates further studies on the critical factors behind the recurrence of the outbreak. Therefore, the present study aims at underlying the reasons behind the epidemics focusing on behaviours of the population and individuals members in Kigamboni Municipal, Dar es Salaaam, Tanzania.

\section{Statement of the Problem}

Cholera outbreak is still a public health problem in Tanzania. It has been in recurrence since 1977. Knowledge level, perceptions and hygiene practices contributes to the Cholera preventive measures that are implemented. Despite the vast body of knowledge on cholera, treatments and prevention measures, Cholera remains a challenge in Kigamboni municipality. The study conducted in Dar es Salaam revealed that the hygiene practices of the community members reflected a lack of knowledge and a negative attitude towards cholera with some misconceptions about the Cholera (Mpazi and Mnyika., 2005). As the levels of knowledge, perceptions and hygiene practices determine the preventive measures needed to combat the recurrence of Cholera; this study assessed the knowledge, perceptions and practices of the heads of households in the Kigamboni community regarding cholera transmission and prevention measures. The study seeks to contribute necessary information for developing effective and efficient policies, strategies and interventions that are easily implementable in the resource scarce areas like Kigamboni municipality in combating the Cholera outbreak.

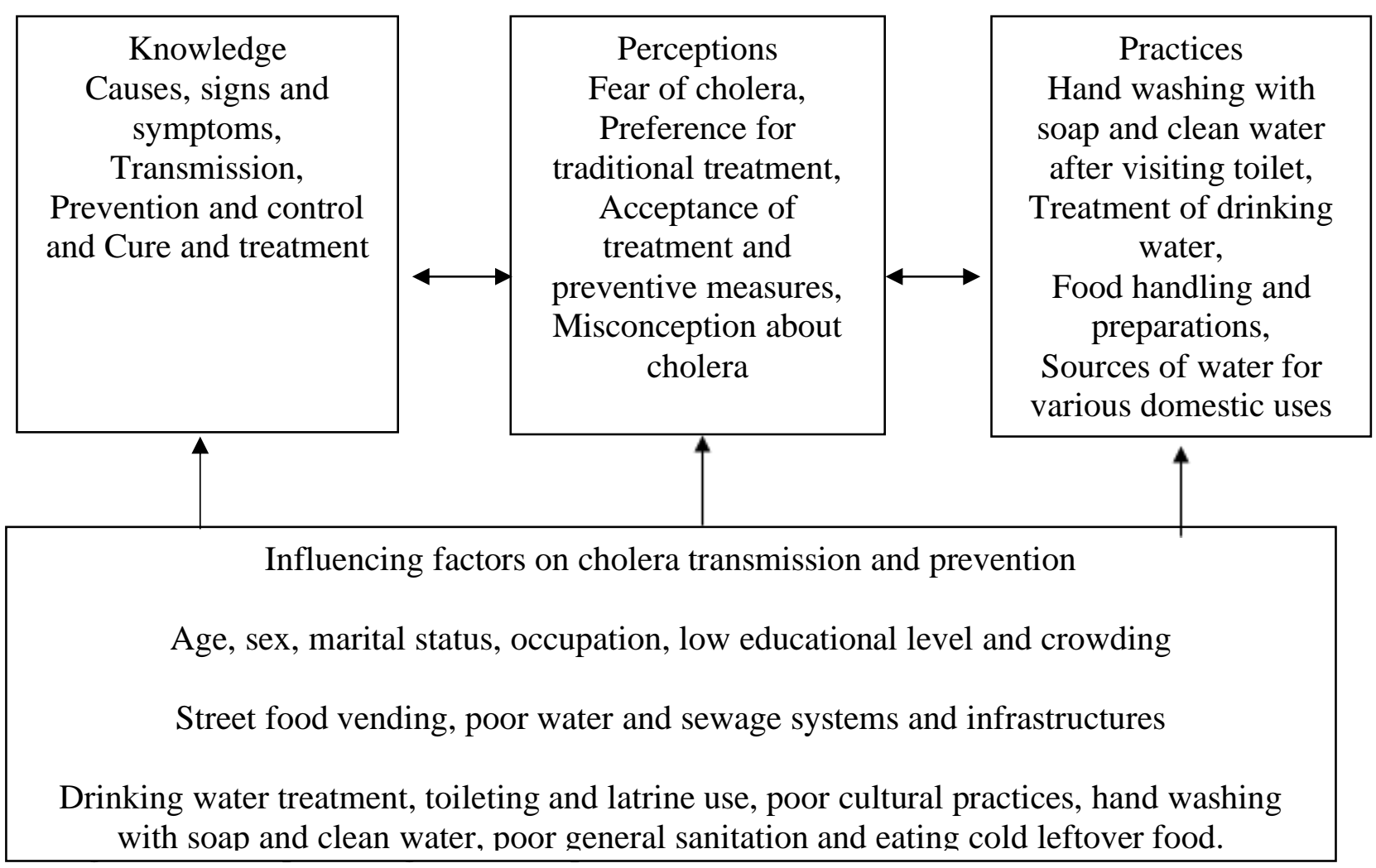

Figure 1: Descriptive diagram/Conceptual framework 


\section{Research Objectives and Rationale of the Study}

The main objective of this study was to assess the Knowledge, Perceptions and Practices on Cholera transmission and prevention measures among heads of household members in Kigamboni Municipality.

The present research study provides the information towards Knowledge, Perceptions and Practices on Cholera transmission and prevention measures among heads of household members in Kigamboni Municipality. The information will be utilized by the policy makers and health management teams in developing efficient and effective policies, strategies and interventions against Cholera in Kigamboni Municipality.

\section{Materials and Methods}

\section{Study Design and Population}

A descriptive cross sectional study was conducted at Kigamboni Municipality. The study was carried out in Kigamboni Municipality in Dar es Salaam in which heads of households were involved. Kigamboni Municipal is characterized with total population of 205,966 according to Tanzania population census of 2012, among them 103,321 females and 102,645 males (Tanzania population census 2012), life expectancy is 62 years for males and 66 years for females (WHO., 2019).

\section{Study Area}

Kigamboni Municipal is an administrative municipality of the Dar es Salaam city in Tanzania. The Municipality originated from Temeke Municipal in 2015 under the government gazette announcement number 462 of 2015 then letter on it become a Municipal in year 2016 (kigambonimc.blogspot.com).

Kigamboni Municipal covers an area of $416 \mathrm{sq} \mathrm{km}$. Administratively it has 9 wards which are Kibada, Kigamboni, Kimbiji, Kisarawe 2, Mjimwema, Pemba Mnazi, Somangila, Tungi and Vijibweni and 67 sub wards. In terms of health services there are 10 government and 5 private dispensaries providing the health services to the residents of the municipal. There are 83 deep wells as the sources of water for different uses, 26 are owned by the local community members and 57 by the government (kigambonimc.blogspot.com).

Kigamboni Municipal is located in the eastern part of Dar es Salaam city and shares its border with Indian Ocean on its northern and eastern parts while the south is bordered with Mkuranga district and on the west with Temeke municipal. There is one tarmac road from Kigamboni Ferry to Kimbiji and Mbagala (kigambonimc.blogspot.com).

\section{Sample Size Selection and Determination}

The heads of households' members were randomly selected from parts of Kigamboni Municipality. Sample size was estimated by using single proportion formula (Wayne, 1987) and the sample size for this study was adjusted to 410 . 


\section{Sampling Procedure}

A multistage sampling method was used to select the study participants. The sampling frame of all 9 wards in Kigamboni Municipal was randomly made and 3 wards were randomly selected. From the selected ward the sampling frame of all villages was randomly made and only 5 villages were randomly selected. From the selected 5 villages the sampling frame was randomly made to randomly select 10 hamlets with ten households each in 4 villages and 1 hamlet with ten households in 1 village was used for the study, from each household, the heads of the households were interviewed.

\section{Variables}

The dependent variables are Knowledge, perception and practice and independent variables are age, sex, marital status, poverty, unemployment, street food vending, poor water and sewage systems and infrastructures, Drinking water treatment, toileting and latrine use, poor cultural practices, hand washing with soap and clean water, poor general sanitation and eating cold leftover food. Generally the practice was measured as good practice or poor practice, the knowledge was assessed as good, moderate or poor depending on the respondent's responses and perception was measured as positive or negative both depending on the responses provided by the respondent in attempting the questions and the number of questions attempted and the correctness of the responses.

\section{Data Collection Instruments and Pre Testing}

The interview schedule was used to collect information. Principal researcher and the two research assistants trained on this study were involved in data collection. Data collection instruments were pre-tested in Mji Mwema ward in Kigamboni Municipality to check the clarity of the questions. The review of questions was made following the outcomes of the pre testing before embarking upon the data collection of the study.

\section{Data Processing and Analysis}

All filled interview schedules were checked daily for completeness after the interview. At the end of interviews, open-ended questions were coded for computer entry. Once data entry was completed, data was cleaned, validated and analyzed using the Statistical Packages for the Social Sciences (SPSS) version 20.0. Chi-squared statistics for contingency tables was used to assess the association between knowledge of cholera, perceptions, practices and influencing factors on cholera transmission and prevention. Statistical significance was assessed using $\mathrm{P}$ values and all results were considered significant if $P \leq 0.05$.

\section{Ethical Issues}

Ethics is a system of moral values that is concerned with the degree to which research procedures adhere to legal, professional and social obligations to the study participants (Polit and Beck, 2008).

Ethical approval for this research study was obtained from MUHAS Ethical Research Committee (Institutional Review Board) and the permission to conduct the study in Kigamboni Municipal was obtained from the Director of Kigamboni Municipal Council, Municipal Medical Officer and the Ward Executive Officers of Kigamboni, Tungi and Vijibweni wards. 


\section{Results and Discussions}

\section{Results}

\section{Socio Demographic Characteristics of The Respondents}

The socio demographic characteristics of the respondents are presented in table 1 . Of the 410 respondents interviewed, 141 (34.4\%) were males while $269(65.6 \%)$ were females. Among the respondents 155 (37.8\%) had the age between 18-24 years old, 191 (46.6\%) the age between 2544 years old and $64(15.6 \%)$ had the age of 45 years and above. The majority of the respondents were Muslim 240 (58.5\%) followed by the Christians 170 (41.5\%).

Most 184 (44.9\%) of the respondents are living in low density area, while others 118 (28.8\%) and $108(26.3 \%)$ lives in medium and high density areas respectively. Among all the respondents 171 $(41.7 \%)$ had primary education, $158(38.5 \%)$ secondary education, 54 (13.2\%) had university education, $21(5.1 \%)$ had college education and few $6(1.5 \%)$ had informal education. Most 194 $(47.3 \%)$ of the houses of the respondents had more than four number of rooms, while others had one room $88(21.5 \%)$, two rooms $48(11.7 \%)$ and three rooms $80(19.5 \%)$ respectively.

Table 1: Social Demographic and personal information

\begin{tabular}{|l|l|l|}
\hline Item & Frequency (n) & Percentage (\%) \\
\hline Sex & 141 & \\
\hline Male & 269 & 34.4 \\
\hline Female & & 65.6 \\
\hline Age & 155 & \\
\hline $18-24$ & 191 & 37.8 \\
\hline $25-44$ & 64 & 46.6 \\
\hline 45 and above & & 15.6 \\
\hline Marital status & 203 & \\
\hline Single & 181 & 49.5 \\
\hline Married & 10 & 44.1 \\
\hline Widowed & 17 & 2.4 \\
\hline Separated & & 4.1 \\
\hline Religion & 240 & \\
\hline Muslim & 170 & 58.5 \\
\hline Christian & & 41.5 \\
\hline Location of home & 108 & \\
\hline High density & 118 & 26.3 \\
\hline Medium density & 184 & 28.8 \\
\hline Low density & 44.9 \\
\hline Level of education & & \\
\hline No formal education & 6 & 1.5 \\
\hline Primary & 171 & 41.7 \\
\hline Secondary & 158 & 38.5 \\
\hline College & 21 & 5.1 \\
\hline University & 54 & 13.2 \\
\hline Number of rooms in house & \\
\hline & & \\
\hline
\end{tabular}




\begin{tabular}{|l|l|l|}
\hline One & 88 & 21.5 \\
\hline Two & 48 & 11.7 \\
\hline Three & 80 & 19.5 \\
\hline Four and above & 194 & 47.3 \\
\hline Occupation of head of the house & \\
\hline Unemployed & 101 & 24.6 \\
\hline Self-employed & 257 & 62.7 \\
\hline Formal employment & 52 & 12.7 \\
\hline
\end{tabular}

\section{Knowledge Regarding Cholera Transmission and Prevention}

Table 2 presents the results on knowledge of cholera among the respondents interviewed in the study. Among 410 respondents, 288 (70.2\%) have knowledge about cholera while 122 (29.8\%) have poor knowledge about cholera.

Most $368(89.8 \%)$ of the respondents identified germs as the causative agent of cholera while few $9(2.2 \%)$ believe witchcraft as the causative agent for cholera and $33(8 \%)$ they never understood the causative agent of cholera. Majority 384 (93.7\%) of the respondents identified severe diarrhea and vomiting as signs and symptoms of cholera while $9(2.2 \%)$ and $17(4.1 \%)$ identified a normal diarrhoeal and vomiting as well as loss of weight as the symptoms of cholera respectively. Majority $203(49.5 \%)$ of the respondents believe that cholera is transmitted through air while $185(45.1 \%)$ believe that it is transmitted through contaminated food and water and few 22 (5.4\%) believe cholera is transmitted through tears.

Majority of respondents $386(94.1 \%)$ suggest the supply of pure water and adequate sanitation as the means of controlling cholera outbreak while the supply of traditional medicines had been suggested by 9 (2.2) and 15 (3.7\%) they know nothing about cholera control ways. Provision of oral rehydration solution (ORS) as the treatment of cholera has been suggested by $284(69.3 \%)$ respondents while others $116(28.3 \%)$ they are not sure and few $10(2.4 \%)$ suggest the provision of traditional medicine as the treatment of cholera.

Table 2: Knowledge on cholera transmission and prevention

\begin{tabular}{|l|l|l|}
\hline Item & Frequency (n) & Percentage (\%) \\
\hline Heard about cholera & & \\
\hline Yes & 389 & 94.9 \\
\hline No & 21 & 5.1 \\
\hline Knowledgeable about cholera & & \\
\hline Yes & 288 & 70.2 \\
\hline No & 122 & 29.8 \\
\hline Heard about cholera trough & & \\
\hline Relative and friends & 176 & 42.9 \\
\hline Media & 209 & 51 \\
\hline Never heard & 25 & 6.1 \\
\hline Seen cholera patients & & \\
\hline Yes & 193 & 47.1 \\
\hline No & 217 & 52.9 \\
\hline
\end{tabular}




\begin{tabular}{|l|l|l|}
\hline Causes of cholera & & \\
\hline Germs & 368 & 89.8 \\
\hline Witchcraft & 9 & 2.2 \\
\hline I don't know & 33 & 8 \\
\hline Symptoms of cholera & & \\
\hline Loss weight & 17 & 4.1 \\
\hline Diarrhea and vomiting & 9 & 2.2 \\
\hline One has severe diarrhea and vomiting & 384 & 93.7 \\
\hline Mode of cholera transmission & 203 & \\
\hline Through air & 185 & 49.5 \\
\hline Through contaminated water and food & 22 & 45.1 \\
\hline Through tears & & 5.4 \\
\hline Ways of preventing cholera & 15 & \\
\hline I don't know & 386 & 3.7 \\
\hline Supply of pure water and adequate sanitation & 9 & 94.1 \\
\hline Take traditional medicine & 2.2 \\
\hline Treatment of cholera & & \\
\hline Give traditional medicine and nurse at home & 10 & 2.4 \\
\hline Give ORS and take to health center/ institution & 284 & 69.3 \\
\hline I am not sure & 116 & 28.3 \\
\hline Heard about cholera vaccine & & \\
\hline Yes & 186 & 45.4 \\
\hline No & 224 & 54.6 \\
\hline
\end{tabular}

\section{Knowledge of Cholera in Relation to Age Groups}

The majority of respondents with high knowledge regarding cholera were found between the age groups of 25-44 (66.7\%), 18-24 (69.2\%) and 45 and above (83.9\%). The difference is statistically significant $(\mathrm{P}<0.05)$.

Table 3: Cross tabulation of knowledge about cholera among the age groups

\begin{tabular}{|c|c|c|c|c|}
\hline \multirow{2}{*}{\multicolumn{2}{|c|}{ Item }} & \multicolumn{2}{|c|}{ Knowledge About Cholera } & \multirow[t]{2}{*}{ Total } \\
\hline & & Yes & No & \\
\hline \multirow[t]{3}{*}{ Age group } & $18-24$ & $108(69.2 \%)$ & $48(30.8 \%)$ & $156(100 \%)$ \\
\hline & $25-44$ & $128(66.7 \%)$ & $64(33.3 \%)$ & $192(100 \%)$ \\
\hline & 45 and above & $52(83.9 \%)$ & $10(16.1 \%)$ & $62(100 \%)$ \\
\hline \multicolumn{2}{|l|}{ Total } & $288(70.2 \%)$ & $122(29.8 \%)$ & $410(100 \%)$ \\
\hline
\end{tabular}

\section{Perceptions on Cholera Transmission and Prevention Measures}

Table 4, presents results on perception concerning cholera transmission and prevention measures among the respondents interviewed in the study. Most 229 (55.9\%) of the respondents had negative perceptions on food sharing on gatherings during the outbreak of Cholera, $72(17.6 \%)$ perceived very bad, 60 (14.6\%) perceived bad, 27 (6.6\%) were not sure and $22(5.4 \%)$ didn't fill badly on food sharing. 
Among the 410 respondents, $462(88.3 \%)$ perceived positively that fruits should be washed before eating, $43(10.5 \%)$ perceived that it should be washed while $5(1.2 \%)$ out of the respondents they were not sure if it should be washed or not before eating. The results revealed that the majority of the community members $380(92.7 \%)$ are interested in in preventing cholera while few showed lack of interest $30(7.3 \%)$.

In this study it has been revealed that the most $369(90 \%)$ residents of Kigamboni are willing to vaccinate themselves and their families while few 20 (4.9\%) are not willing probably due to lack of knowledge on vaccination and $21(5.1 \%)$ don't understand the same falls under the lack of knowledge.

Table 4: Perceptions on Cholera Transmission and Prevention

\begin{tabular}{|l|l|l|}
\hline Item & Frequency (n) & Percentage (\%) \\
\hline Feelings about food sharing & 229 & 55.9 \\
\hline Strongly bad & 72 & 17.6 \\
\hline Not very bad & 60 & 14.6 \\
\hline Bad & 22 & 5.4 \\
\hline Strongly okay & 27 & 6.6 \\
\hline Not sure & & \\
\hline Fruits washing before eating & 362 & 88.3 \\
\hline Strongly agree & 43 & 10.5 \\
\hline Agree & 5 & 1.2 \\
\hline Not sure & 260 & \\
\hline Reason behind the rise in street vending & 63.4 \\
\hline Increase in poverty levels & 38 & 9.3 \\
\hline Encouragement from political leaders & 81 & 19.8 \\
\hline Increase in population & 31 & 7.6 \\
\hline I don't know & & \\
\hline Interest in preventing cholera & 380 & 92.7 \\
\hline Yes & 30 & 7.3 \\
\hline No & & \\
\hline Willingness to vaccination & 369 & 90 \\
\hline Yes & 20 & 4.9 \\
\hline No & 21 & 5.1 \\
\hline Don't know & & \\
\hline Willingness to vaccinate the family & 376 & 91.7 \\
\hline Yes & 8 & 2.9 \\
\hline No & 12 & \\
\hline Don't know & 14 & \\
\hline Refused & & \\
\hline & 31 & \\
\hline & & \\
\hline
\end{tabular}

\section{Perceptions on Food Sharing in Relation to Age Group}

Regarding the perception of food sharing in gatherings during cholera outbreak among the age groups, majority $87(57.2 \%), 110(57.6 \%)$ and $32(47.8 \%)$ perceived strongly bad on gathering food sharing during cholera outbreak among 18-24, 25-44 and above 44 age groups. The difference 
is statistically significant $(\mathrm{P}<0.007)$. Table 5 , presents a cross tabulation of perception concerning food sharing among the age groups.

Table 5: Cross tabulation of perception about food sharing among the age groups

\begin{tabular}{|l|c|c|c|c|c|c|c|}
\hline \multicolumn{2}{|l|}{ Item } & \multicolumn{5}{|c|}{ Feeling about food sharing on gatherings } & \multirow{2}{*}{ Total } \\
\hline \multicolumn{2}{|c|}{} & $\begin{array}{c}\text { Strongly } \\
\text { bad }\end{array}$ & Not bad & bad & Okay & Not sure & \\
\hline \multirow{2}{*}{$\begin{array}{l}\text { Age } \\
\text { group }\end{array}$} & $18-24$ & $87(57.2 \%)$ & $20(13.2 \%)$ & $24(15.8 \%)$ & $9(6.0 \%)$ & $12(7.9 \%)$ & $\mathbf{1 5 2 ( 1 0 0 \% )}$ \\
\cline { 2 - 8 } & $25-44$ & $110(57.6 \%)$ & $38(19.9 \%)$ & $23(12 \%)$ & $11(5.8 \%)$ & $9(4.8 \%)$ & $\mathbf{1 9 1}(\mathbf{1 0 0 \% )}$ \\
\cline { 2 - 8 } & $>44$ & $32(47.8 \%)$ & $14(20.9 \%)$ & $13(19.4 \%)$ & $2(3.0 \%)$ & $6(9.0 \%)$ & $\mathbf{6 7}(\mathbf{1 0 0 \%})$ \\
\hline \multicolumn{2}{|l|}{ Total } & $\mathbf{2 2 9}(\mathbf{5 5 . 9 \%})$ & $\mathbf{7 2 ( 1 7 . 6 \% )}$ & $\mathbf{6 0 ( 1 4 . 6 \% )}$ & $\mathbf{2 2 ( 5 . 4 \% )}$ & $\mathbf{2 7}(\mathbf{6 . 6 \%})$ & $\mathbf{4 1 0}(\mathbf{1 0 0 \%})$ \\
\hline
\end{tabular}

\section{Practices regarding Cholera Transmission and Prevention}

World health organization advocates that the long term solution for cholera control lies in economic development and universal access to safe drinking water and adequate sanitation. That is to ensure use of safe water, basic sanitation and good hygiene practices in cholera hotspots (WHO, 2019). Table 6, frequency table showing respondents practices regarding cholera transmission and prevention measures.

The results of this study revealed that the majority of the respondents $260(63.5 \%)$ use piped water as their source of drinking water, $68(16.6 \%)$ use water from venders and $60(14.7 \%)$ use well water, however $13(3.2 \%)$ among 60 (14.7\%) use water from unprotected wells as their source of drinking water. The study findings showed that the most of the residents $315(76.8 \%)$ treat while $74(18 \%)$ do not treat water to make it safe for drinking. However among them few 139 (33.9\%) of treat drinking water often

In this study it has been revealed that the majority of the community members $328(80 \%)$ are regular in hand washing while few 64 (15.6\%) wash occasionally. Among the repondents384 (93.7\%) wash their hands after visiting toilets while $26(6.3 \%)$ don't wash. Again it is revealed that most $363(88.5 \%)$ of the respondents possess soap and detergents at their homes for washing hands and other domestic use. Most 305 (74.4\%) of the majority will rush the cholera patient to the nearest treatment center while 73 (7.8\%) will give ORS (Oral Rehydration Solution) to a person developed cholera.

Table 6: Practices on Cholera Transmission and Prevention

\begin{tabular}{|l|l|l|}
\hline Item & Frequency (n) & Percentage (\%) \\
\hline Source of drinking water & & \\
\hline Piped water, in house & 170 & 41.5 \\
\hline Piped water, in court & 49 & 12 \\
\hline Piped water, public & 41 & 10 \\
\hline Communal standpipe & 22 & 5.4 \\
\hline Well, protected & 13 & 3.2 \\
\hline Well, unprotected & 13 & 3.2 \\
\hline Well with pump & 34 & 8.3 \\
\hline Water truck /water vendor & 68 & 16.6 \\
\hline Water treatment to make it safe to drink & \\
\hline
\end{tabular}




\begin{tabular}{|l|l|l|}
\hline Yes & 315 & 76.8 \\
\hline No & 74 & 18 \\
\hline Don't know & 21 & 5.1 \\
\hline How often water treatment is done & & \\
\hline All the time & 139 & 33.9 \\
\hline Most of the time & 92 & 22.4 \\
\hline Sometimes & 94 & 22.9 \\
\hline Did not treat water during past 6 months & 85 & 20.7 \\
\hline Regularity in hand washing & & \\
\hline Yes & 328 & 80 \\
\hline Occasionally & 64 & 15.6 \\
\hline No & 18 & 4.4 \\
\hline Washing hands after using toilet & & \\
\hline Yes & 384 & 93.7 \\
\hline No & 26 & 6.3 \\
\hline Presence of soap or detergent in the house & & \\
\hline Yes & 363 & 88.5 \\
\hline No & 25 & 6.1 \\
\hline Don't know & 22 & 5.4 \\
\hline Refuse disposal & & \\
\hline Dust bin/ bags & 250 & 61 \\
\hline Dugout rubbish pit & 144 & 35.1 \\
\hline Open space & 8 & 2 \\
\hline Other specify & 8 & 2 \\
\hline Getting rid of the disposed refuse completely & \\
\hline By burning & 191 & 46.6 \\
\hline By burring & 42 & 10.2 \\
\hline Through the local authority & 160 & 39 \\
\hline Other means & 17 & 4.1 \\
\hline Practice on fruits before eating & & \\
\hline Wash before eating & 366 & 89.3 \\
\hline Pearl before eating & 25 & 6.1 \\
\hline Sometimes wash and sometimes not & 10 & 2.4 \\
\hline I don't do anything & 9 & 2.2 \\
\hline Keeping the leftover food & & \\
\hline Cover the food & 303 & 73.9 \\
\hline Refrigerate & 107 & 26.1 \\
\hline Practice on leftover food before eating & & \\
\hline Heat before eating & 378 & \\
\hline Eaten cold & 16 & \\
\hline Thrown away & & \\
\hline
\end{tabular}




\begin{tabular}{|l|l|l|}
\hline \multicolumn{2}{|l|}{ POI: 10.5281/zenodo.3 } \\
\hline Practice when a member of the household develops cholera & \\
\hline Give Oral Rehydration Salt & 20 & 4.9 \\
\hline Rush the individual to the health facility & 73 & 7.8 \\
\hline Nothing & 305 & 74.4 \\
\hline Drinking water boiling to make it safe & 12 & 2.9 \\
\hline Yes & 343 & \\
\hline No & 67 & 83.7 \\
\hline
\end{tabular}

\section{Practices on Boiling Drinking Water Among the Age Groups}

Among the respondents age groups majority 140 (91.5\%), 145 (78.8\%) and 50 (76.9\%) of them boil their drinking water to make it safe among the age groups 18-24, 25-44 and 45 years and above respectively. The difference is statistically significant $(\mathrm{P}<0.05)$.

Table 7: Cross tabulation of boiling tendency to make water safe among the age groups

\begin{tabular}{|c|c|c|c|c|}
\hline \multirow{2}{*}{\multicolumn{2}{|c|}{ Item }} & \multicolumn{2}{|c|}{ Boiling water to make safe } & \multirow{3}{*}{$\begin{array}{c}\text { Total } \\
153(100 \% \\
\end{array}$} \\
\hline & & Yes & No & \\
\hline \multirow[t]{3}{*}{ Age group } & 18-24 & $140(91.5 \%)$ & $13(8.5 \%)$ & \\
\hline & $25-44$ & $145(78.8 \%)$ & $39(21.2 \%)$ & $184(100 \%)$ \\
\hline & $>45$ & $50(76.9 \%)$ & $15(23.1 \%)$ & $65(100 \%)$ \\
\hline \multicolumn{2}{|l|}{ Total } & $343(83.7 \%)$ & $67(16.3 \%)$ & $410(100 \%)$ \\
\hline
\end{tabular}

\section{Discussions}

\section{Knowledge on Cholera Transmission and Prevention Measures}

This study aimed at assessing the knowledge, perceptions and practices regarding Cholera transmission and prevention. Results showed that among 410 respondents, $70.2 \%$ had knowledge about Cholera; respondents identified germs as the causative agent of cholera, severe diarrhea and vomiting as signs and symptoms of cholera and identified that Cholera is transmitted through contaminated food and water. Similar study where conducted in Dar es Salaam, Tanzania where by $85 \%$ of the respondents possessed knowledge of cholera (Mpazi et al., 2005). However, this study also revealed a negative belief on the mode of transmission of cholera, that it is transmitted through air and tears. Studies conducted in Dar es Salaam and Haiti reported negative belief among the community members studied (Mpazi et al., 2005 and Valery et al., 2011).

Respondents in this study revealed that the supply of pure water and adequate sanitation is a key prevention measures in controlling cholera outbreak in Kigamboni. WHO report of 2019 recommends the supply of pure water and adequate sanitation as standard control and prevention measures against Cholera (WHO., 2019). However similar study were conducted in Nigeria and revealed that the provision of safe and clean water as well as good environmental hygiene as control and prevention measures against Cholera outbreak (Adeneye et al., 2016).

According to WHO, Vaccine - Preventable Disease Surveillance Standards of 2019 recommends that treatment of Cholera should depends on severity of illness and level of dehydration and that severe cases need intravenous rehydration and antibiotics, Milder cases can be treated with an 
Oral Rehydration Solution and zinc supplementation should also be given to children $<5$ years of age (WHO., 2019). In this study the respondents suggested the provision of Oral Rehydration Solution (ORS) as the treatment of Cholera which concords to the recommendations of World Health Organization (WHO). Similar understanding and knowledge about Oral Rehydration Solution (ORS) where revealed in studies conducted in Notre dame, Dhaka Bangladesh and Nigeria (Guzman J. C., 2013, Tasnuva et al., 2013 and Valery et al., 2010).

\section{Perceptions on Cholera Transmission and Prevention Measures}

This study found out that the respondents had positive perceptions about food sharing on gatherings during the Cholera Outbreak this indicated a positive perception about Cholera, also respondents perceived that fruits should be washed before eating which is one among the methods of preventing Cholera transmission. The studies conducted in Bangladesh revealed that the majority of the respondents had positive perception about Cholera with regards to food sharing and fruits washing (Tasnuva et al., 2013). Again, in this study it has been found out that there is a relationship between perceptions of food sharing in gatherings during cholera outbreak and the age groups. The difference is statistically significant $(\mathrm{P}<0.007)$.

The present study suggest that the majority of the respondents are interested in preventing Cholera and are willing to vaccinate themselves and their families in prevention of Cholera. These findings are vital in planning for the vaccination program and campaign in the area in an effort to prevent Cholera Outbreaks. These findings concords to the findings of the study conducted in Haiti, where many people were found to be willing to vaccination (Louise et al., 2016).

\section{Practices on Cholera Transmission and Prevention Measures}

The outbreak of Cholera could be attributed to transmission through faecally contaminated water (Adeneye et al., 2016). This study revealed that the majority of the respondents use piped water and well water as their source of drinking water; however, water treatment, treatments of wells and covering of the wells had been a challenge to the respondent's interviewed. This may lead to the drinking of Vibrio Cholerae contaminated water and finally leads to the transmission of the Cholera. The studies conducted in Hait, Dar es Salaam and Notre dame its respondents mentioned piped water and well water as the sources of drinking water however the challenges were on the treatments of the water sources and water itself (Adeneye et al., 2016, Mpazi et al., 2005 and Guzman J. C., 2013).

The findings of this study revealed that the respondents treat water to make it safe for drinking through boiling and Chlorination or bleach solution. Water treatment is one of the methods used in prevention and control of Cholera. Several studies have reported the use of choline or bleach solution, water treatment tablets and boiling as the methods of water treatments to make drinking water safe for drinking and hence preventing Cholera Outbreaks and its transmissions (Mpazi et al., 2005, Lana et al., 2016, Adeneye et al., 2016, Guzman J. C., 2013, Megan et al., 2001 and Valery et al., 2011).

WHO recommends that preventive efforts should include promotion of hand-washing and safe food handling practices (WHO., 2019). The waste disposals and hand wash practices are essential practices in fighting against cholera; however, pits should be treated to avoid multiplication of cholera germs (Zohura et al., 2016). In this study the results revealed that the majority of the 
respondents ware regular in hand washing with soap and clean water, wash their hands after visiting toilets, poses soap and detergents at their homes for washing hands and wash fruits before eating, however there were slackness in its implementation.

These findings revealed that the practices needs to be improved towards prevention of Cholera Outbreaks and similar findings on practices has been reported by studies done in Dar es Salaam, Notre dame, Madagascar and Haiti (Mpazi et al., 2005, Guzman J. C., 2013, Megan et al., 2001 and Valery et al., 2011).

The study conducted in Madagascar revealed that consumption of the cold leftover food had significance in Cholera transmission (Megan et al., 2001). In this study it has been found out that the majority of the respondents covers and refrigerate the leftover food and most of the respondents heat the leftover food before eating in an effort of preventing Cholera Transmission.

Practices when a family member develops a Cholera has been revealed in this study that majority of respondents will give ORS (Oral Rehydration Solution) and rush the cholera patient to the nearest Cholera Treatment Center (CTC). Study conducted in Nigeria, Haiti and Dar es Salaam, recommended on the provision of a documented guidance to the Cholera Treatment Centers and the supply of Oral Rehydration Salt (ORS) packets so as to improve Cholera patient management and treatment. (Adeneye et al., 2016, Lana et al., 2016 and McCrickard et al., 2017).

Among the respondents age groups majority $91.5 \%, 78.8 \%$ and $76.9 \%$ of them boil their drinking water to make it safe among the age groups 18-24, 25-44 and 45 years and above respectively. The difference is statistically significant $(\mathrm{P}<0.05)$.

\section{Conclusions and Recommendations}

\section{Conclusion}

The study was carried out to seek the Knowledge, Attitude and Practice on Cholera transmission and prevention measures at Kigamboni Municipal. The study revealed that the majority of the respondents had good knowledge on cholera; the majority had average Practices and positive Perceptions towards the transmission and prevention of cholera. The study has revealed that $70.2 \%$ of the respondents had knowledge on cholera regarding its causes, symptoms and signs, transmission, treatments and its prevention measures. It was also found out that the respondents had positive perceptions in Cholera transmissions and prevention measures as most $92.7 \%$ were interested in Cholera prevention and willing to vaccination.

Furthermore the results indicated that the respondents had an average practices with regards to Cholera transmission and prevention measures as $63.5 \%$ use the pipe water as their source of drinking water and among them only $76.8 \%$ treat water to make it safe for drinking and $80 \%$ are regular in washing their hands with soap after and before food, visiting toilets and preparations of foods. 


\section{Recommendations}

The study had revealed that majority of the respondents agreed on the supply of Oral Rehydration Solution (ORS) sachets, pure water, adequate sanitations and vaccination as the control and prevention measures against Cholera Outbreak in Kigamboni Municipality.

The following are the recommendations made based on the findings of this study, awareness creations among the residents of Kigamboni Municipality regarding practices which facilitate the spread of Cholera, removal of misconception with regards to the causes of Cholera and its modes of transmissions, well water used as the sources of drinking water should be treated regularly and protected all the time and the supply of Oral Rehydration Solution (ORS) sachets, pure water, vaccination, adequate and proper sanitations to the Kigamboni Municipality by the Government. However, future studies should be planned to investigate on the effectiveness and efficiency of knowledge, health policies and health related in addressing the Cholera Outbreak Challenge.

\section{Acknowledgements}

First and foremost, all thanks to God for the whole thing that I am and will be. Without God, I am nothing. The Blessings are evident regardless of the challenges that were encountered; it reminds me that in trusting almighty God, everything is possible.

I would like to convey my special thanks to the Centre for Diseases Control (CDC), School of Public Health and Social Science (SPHSS) of Muhimbili university of Health and allied science for the financial support and time which facilitated the successful completion of this study.

I appreciate the Kigamboni Municipal for the support and permission to undertake this study and special appreciation also goes to all the research participants for accepting to participate in this study. I wish to acknowledge health representatives of Kigamboni, Kisiwani and Tungi wards for agreeing to participate and for their valuable time spent in the study especially during data collections. I am indebted to my research assistant Mr. Rajabu Mkieti and Ponsian Peter Kunambi for their support in data collection and analysis. 


\section{Appendices}

\section{MUHIMBILI UNIVERSITY OF HEALTH AND ALLIED SCIENCES OFFICE OF THE DIRECTOR OF POSTGRADUATE STUDIES}

P.O. Box 65001

DAR ES SALAAM

TANZANIA

Web: www.muhas.ac.tz

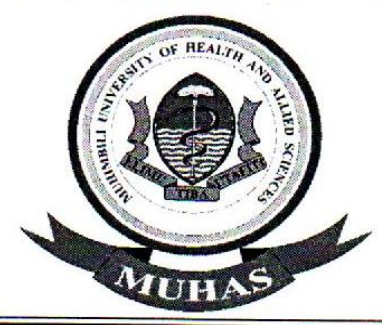

Tel G/Line: +255-22-2150302/6 Ext. 1(

Direct Line: $+255-22-2151378$

Telefax: $+255-22-2150465$

E-mail: dpgs@muhas.ac.tz

Ref. No. DA.287/298/01A/

15th August, 2018

Mr. Ramadhani H. Nauja

MPH-Distance Learning

MUHAS.

\section{RE: APPROVAL OF ETHICAL CLEARANCE FOR A STUDY TITLED: "KNOWLEDGE, PERCEPTIONS AND PRACTICES ON CHOLERA TRANSMISSION AND PREVENTION AMONG HEADS OF HOUSEHOLD MEMBERS AGED 18 YEARS AND ABOVE IN KIGOMBONI MUNICIPALITY, DAR ES SALAAM, TANZANIA"}

Reference is made to the above heading.

I am pleased to inform you that, the Chairman has, on behalf of the Senate, approved ethical clearance for the above-mentioned study. Hence you may proceed with the planned study.

The ethical clearance is valid for one year only, from 14th August, 2018 to 13th August 2019. In case you do not complete data analysis and dissertation report writing by 13th August, 2019, you will have to apply for renewal of ethical clearance prior to the expiry date.

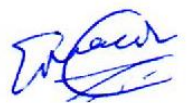

Dr. Emmanuel Balandya

ACTING: DIRECTOR OF POSTGRADUATE STUDIES

cc: Director of Research and Publications

cc: Dean, School of Public Health and Social Sciences

Appendix 1: Approval of Ethical Clearance 


\section{MUHIMBILI UNIVERSITY OF HEALTH AND ALLIED SCIENCES OFFICE OF THE DIRECTOR OF POSTGRADUATE STUDIES}

P.O. Box 65001

DAR ES SALAAM

TANZANIA

Web: www.muhas.ac.tz

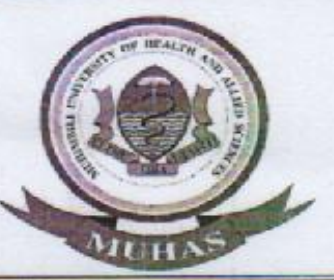

Tel G/Line: $+255-22-2150302 / 6$ Ext. 1015

Direct Line: $+255-22-2151378$

Telefax: +255-22-2150465

E-mail: dpgs@muhas.ac.tz

Ref. No. HD/MUH/T.426/2015

16th August, 2018

Director,

Kigamboni Municipal Council

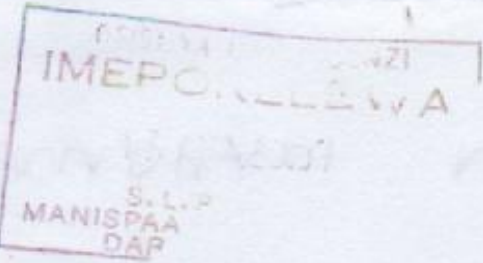

DAR ES SALAAM.

\section{Re: INTRODUCTION LETTER}

The bearer of this letter Mr. Ramadhani H. Nauja is a student at Muhimbili University of Health and Allied Sciences (MUHAS) who is pursuing MPH-Distance Learning.

As part of his studies he intends to do a study titled:"Knowledge, perceptions and practices on cholera transmission and prevention among heads of household members aged 18 years and above in Kigamboni Municipality, Dar es Salaam, Tanzania ".

The research has been approved by the Chairman of University Senate.

Kindly provide him the necessary assistance to facilitate the conduct of his research.

We thank you for your cooperation.

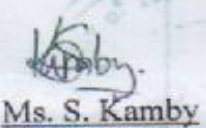

For: DIRECTOR, POSTGRADUATE STUDIES

cc: Dean, School of Medicine.

cc: Mr. Ramadhani H. Nauja

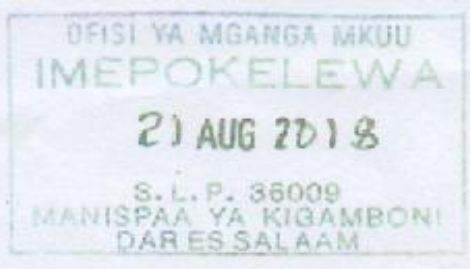

Appendix 2: MUHAS Introduction Letter to Kigamboni Municipal 


\section{KIGAMBONI MUNICIPAL COUNCIL}

[All letters should addressed to Municipal Director of Kigamboni]

Tell: +255 22-2928468

Fax: +255 22-2928469

E-mail: info@kigamboni.go.tz

Tovuti: www.kigamboni.go.tz

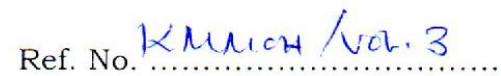

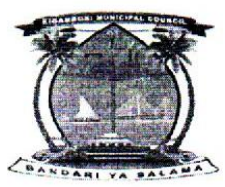

P.O.Box 36009, KIGAMBONI, DAR ES SALAAM, TANZANIA.

To...................

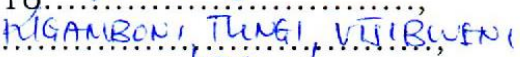

P.O. BOX 36009

DAR ES SALAAM

Dear Sir/Madam

Date: $21 \mid \log 10018$

\section{REF: PERMISSION TO CONDUCT HEALTH RESEARCH ACTIVITIES IN KIGAMBONI MUNICIPALITY}

Please refer to the above heading.

Extension of permission has been granted to Mr/Mrs/Miss / Prof/Dr. RAMADitANi...H........S A... from (institution).............. address For Tel No. to collect data for research.

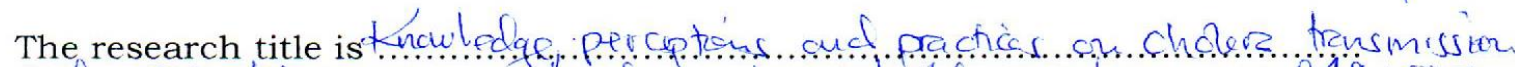

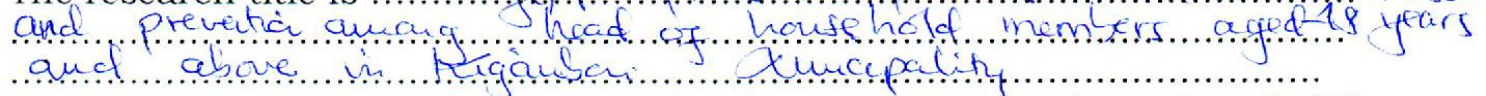
She/he has submitted the proposal for the mentioned study to the MMOH Office as a pre - condition prior to authorization.

The researchers have been instructed and agreed to submit the research progress reports and final results to the $\mathrm{MMOH}$ prior to any publications Data collection will restart on 23.08 .204 to $4.19 .4 .8 .$. sample size

inis research work is part of Academic for fulfillment for Diploma/Advanced Diploma/Degree/Master/PHD it is part on going research in your Institution.

Your sincerely.

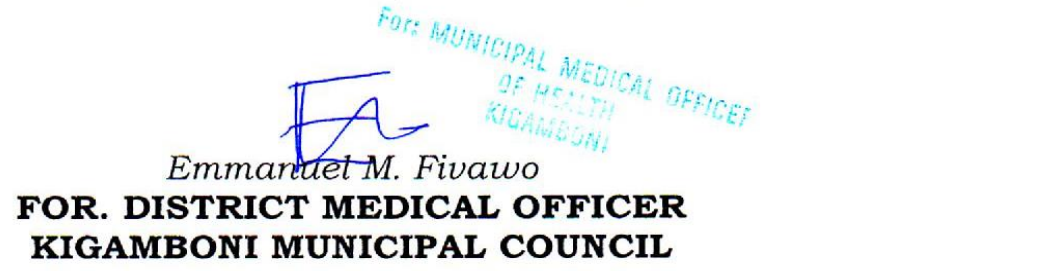

Appendix 3: Kigamboni Municipal permission to conduct Health Research 


\section{References}

[1] Acosta, J. C., Claudia, M. Galindo, Kimario. J. Senkoro, K. Urassa, H. Casals,C. Corachán, N.M. Eseko, Marcel, T. Mshinda, H. Lwilla, F. Vila,J. and Pedro L. lonso, A. (2001). Cholera Outbreak in Southern Tanzania: Risk Factors and Patterns of Transmission. Journal of emerging infectious diseases. Vol.7, p 201-208.

[2] Adeneye, A.K., A.Z. Musa, K.S. Oyedeji, D. Oladele, M. Ochoga, K.A. Akinsinde, M.T. Niemogha, F.O. Nwaokorie, T.A. Bamidele, and B.I. Brai (2016). "Risk factors associated with cholera outbreak in Bauchi and Gombe States in North East Nigeria." Journal of Public Health and Epidemiology 8, no. 11 (2016): 286-296.

[3] Ali M, Emch M, Donny JP, Yunus M, \& Sack RB (2002). Identifying environmental risk factors for endemic cholera a raster GIS approach. (Pub Med) Health Place: 2002 Sep: 8(3): 201-10.

[4] Ali M, Nelson AR, Lopez AL, Sack DA (2015) Updated Global Burden of Cholera in Endemic Countries. PLoS Negl Trop Dis 9(6): e0003832.

[5] Gretchen Cowman, Shikanga Otipo, Ian Njeru, Thomas Achia, Harsha Thirumurthy, Jamie Bartram, Jackson Kioko (2017). Factors associated with cholera in Kenya, 2008-2013. The Pan African Medical Journal. 2017; 28:101. doi:10.11604/pamj.2017.28.101.12806

[6] Fatema Zohura, Sazzadul Islam Bhuyian, Shirajum Monira, Farzana Begum, Shwapon K. Biswas, Tahmina Parvin, David Sack, R. Bradley Sack, Elli Leontsini, K. M. Saif-Ur-Rahman, Mahamudur Rashid, Rumana Sharmin, Xiaotong Zhang, Munirul Alam, Christine Marie George (2016). "Observed Handwashing with Soap Practices Among Cholera Patients and Accompanying Household Members in a Hospital Setting (CHoBI7 Trial)". The American Journal of Tropical Medicine and Hygiene, Volume 95, Issue 6, Dec 2016, p. 1314 - 1318

[7] Harris JB, LaRocque RC, Qadri F, Ryan ET, Calderwood SB (2012). Cholera. Lancet 379: 246676.

[8] Jerry E. Sibiya and Jabulani Ray Gumbo (2013). Knowledge, Attitude and Practices (KAP) Survey on Water, Sanitation and Hygiene in Selected Schools in Vhembe District, Limpopo, South Africa. Int. J. Environ. Res. Public Health 2013, 10, 2282-2295

[9] Jonathan Lilje, Hamit Kessely and Hans-Joachim Mosler (2015). Factors Determining Water Treatment Behavior for the Prevention of Cholera in Chad. Am. J. Trop. Med. Hyg., 93(1), 2015, pp. 57-65

[10] Juan Carlos Guzman (2013). "KAP evaluation report of cholera prevention programming activities through crs partner hospitals and caritas health centers." University of Notre Dame, 2013.

[11] Kadaleka, S. (2011). Assessing the effect of nutrition and treatment in cholera dynamics: The case of Malawi: A dissertation submitted in partial fulfillment of the requirement for the Degree of masters of Science Mathematical Modeling of the University of Dar es Salaam.

[12] Kigamboni municipal blog, kigambonimc.blogspot.com, reaccessed on 25/06/2019.

[13] Lana Childs, Jeannot François, Alina Choudhury, Kathleen Wannemuehler, Amber Dismer, Terri B. Hyde, Catherine Y. Yen, Kashmira A. Date, Stanley Juin, Mark A. Katz, Erica Felker Kantor, Janell Routh, Melissa Etheart, Tracie Wright, Paul Adrien, Rania A. Tohme (2016). "Evaluation of Knowledge and Practices Regarding Cholera, Water Treatment, Hygiene, and Sanitation Before and After an Oral Cholera Vaccination Campaign-Haiti, 2013-2014" The American Journal of Tropical Medicine and Hygiene, Volume 95, Issue 6, Dec 2016, p. 1305 - 1313.

[14] Lindi J. B. (2010). Behavioural factors associated with cholera outbreaks in Kilosa, Tanzania. A Dissertation submitted for a partial fulfilment of MPH degree, Muhimbili University of health and allied sciences.

[15] Lindsey S. McCrickard, Amani Elibariki Massay, Rupa Narra, Janneth Mghamba, Ahmed Abade Mohamed, Rogath Saika Kishimba, Loveness John Urio, Neema Rusibayamila, Grace Magembe, Muhammud Bakari, James J. Gibson, Rachel Barwick Eidex, and Robert E. Quick (2017). "Cholera 
Mortality during Urban Epidemic, Dar es Salaam, Tanzania, August 16, 2015-January 16, 2016" Emerg Infect Dis. 2017 Dec; 23 (Suppl 1): S154-S157.

[16] Louise C Ivers, Isabelle J Hilaire, Jessica E Teng, Charles P Almazor, J Gregory Jerome, Ralph Ternier, Jacques Boncy, Josiane Buteau, Megan B Murray, Jason B Harris, Molly F Franke (2015). Effectiveness of reactive oral cholera vaccination in rural Haiti: a case-control study and biasindicator analysis. Lancet Glob Health 2015; 3: e162-68

[17] Makuza N. J. (2002). Factors associated with a Cholera outbreak in Dar es Salaam city. A Dissertation submitted for a partial fulfilment of MPH degree, University of Dar es Salaam.

[18] Marin MA, Thompson CC, Freitas FS, Fonseca EL, Aboderin AO, et al. (2013) Cholera Outbreaks in Nigeria Are Associated with Multidrug Resistant Atypical El Tor and Non O1/Non-O139 Vibrio cholerae. PLoS Negl Trop Dis 7(2): e2049.

[19] Mbunda T.A.F (2011). Street children economic empowerment: a case study of street children in Kigamboni ward, Temeke municipal council in Dar es Salaam region. A Dissertation submitted for a partial fulfilment of Degree of masters in community economic development of the open university of Tanzania.

[20] Megan E. Reller, MD, Yves J. M. Mong, MSc, Robert M. Hoekstra, PhD, and Robert E. Quick, MD, MPH (2001). "Cholera Prevention With Traditional and Novel Water Treatment Methods: An Outbreak Investigation in Fort-Dauphin, Madagascar.” Am J Public Health. 2001 October; 91(10): $1608-1610$.

[21] MoH, Health Information and Research Section. Health Statistics (abstract). Tanzania (July 1998) 6 (1) Morbidity and Mortality data pp. 11,12,55,58.

[22] Ncube, A., Jordaan, A.J. \& Mabela, B.M., 2016, 'Assessing the knowledge, attudes and practces regarding cholera preparedness and preventon in Ga-Mampuru village, Limpopo, South Africa', Jàmbá: Journal of Disaster Risk Studies 8(2), Art. \#164, 9 pages. htp://dx.doi. org/10.4102/jamba.v8i2.164

[23] Polit, D. F. and Beck C.T., (2008). "Nursing Research", 8th Edition, Walters Kluwes PvtLtd, New Delhi, India.

[24] Phiri, P., Nzala, S. H. and Baboo, K. S. (2015). Factors Associated With the Recurring Cholera Outbreaks in Sinazongwe District of Southern Zambia. Medical Journal of Zambia, Vol. 42, No. 4: 184-192 (2015).

[25] Regarding Cholera out Breaks in Illala Municipality of Dar Es Salaam Region,Tanzania, East African Journal of Public Health, Vol 2, No. 2, 2005.

[26] Tasnuva Wahed, Sheikh Shah Tanvir Kaukab, Nirod Chandra Saha, Iqbal Ansary Khan, Farhana Khanam, Fahima Chowdhury, Amit Saha, Ashraful Islam Khan, Ashraf Uddin Siddik, Alejandro Cravioto, Firdausi Qadri, Jasim Uddin (2013). "Knowledge of, attitudes toward, and preventive practices relating to cholera and oral cholera vaccine among urban high-risk groups: findings of a cross-sectional study in Dhaka, Bangladesh.” BMC Public Health, 2013, 13:242.

[27] URT (2005). Tanzania Demographic and Health Survey National bureau of statistics Dar es Salaam Tanzania. www.nbs.go.tz

[28] Valery E.M. Beau De Rochars, Julie Tipret, Molly Patrick, Lara Jacobson, Kamil E. Barbour, David Berendes, Diana Bensyl, Cathie Frazier, Jean W. Domercant, Roodly Archer, Thierry Roels, Jordan W. Tappero, and Thomas Handzel (2011). "Knowledge, Attitudes, and Practices Related to Treatment and Prevention of Cholera, Haiti, 2010” Emerg Infect Dis. 2011 Nov; 17(11): 21582161.

[29] Mpazi, Veronica. AM, Mnyika, Kagoma.S (2005). Knowledge, Attitude Practice Regarding Cholera Out Breaks in Illala Municipality of Dar Es Salaam Region, Tanzania, Bioline International, East African Journal of Public Health, Vol 2, No. 2, 2005, East African Public Health Association Tanzania.

[30] World health organization (WHO). Cholera Fact sheet Updated August 2017 http://www.who.int/mediacentre/factsheets/fs107/en/. Accessed on 25/06/2019 
[31] World health organization, global task force on cholera control, cholera country profile: united republic of Tanzania, 7 April 2008.

[32] World health organization, global task force on cholera control, cholera country profile: united republic of Tanzania, 9 May 2019.

[33] World health organization, Vaccine-Preventable Diseases Surveillance Standards, 2019.

*Corresponding author.

E-mail address: rnauja@ gmail.com 